\title{
Potential of NMR Spectroscopy in the Characterization of Nonconventional Oils
}

\author{
Abdul Majid and Indu Pihillagawa \\ NRC Energy, Mining and Environment Portfolio, National Research Council of Canada, Ottawa, ON, Canada K1A 0R6 \\ Correspondence should be addressed to Abdul Majid; abdul.majid@nrc.gc.ca
}

Received 9 April 2013; Accepted 25 August 2013; Published 2 January 2014

Academic Editors: E. M. Cuerda-Correa, X. Lu, and O. Senneca

Copyright (C) 2014 A. Majid and I. Pihillagawa. This is an open access article distributed under the Creative Commons Attribution License, which permits unrestricted use, distribution, and reproduction in any medium, provided the original work is properly cited.

\begin{abstract}
NMR spectroscopy was applied for the characterization of two biomass based pyrolysis oil samples. The samples were extracted in various solvents and the extracts were investigated by both ${ }^{1} \mathrm{H}$ and ${ }^{13} \mathrm{C}$ NMR spectroscopy. Subsequent evaluation of the integrated analytical data revealed chemical information regarding semiquantitative estimation of various functional groups. This information could not have been obtained readily from the individual spectroscopic techniques. Semiquantitative estimation of the various functional groups allowed a comparison of the extraction efficiency of these groups in various solvents. The method is based on the premise that although the number of individual molecular species in pyrolysis oil liquid is large, most of these species are composed of a limited number of functional groups. The methodology provided information on the concentration of chemical functionalities that are potentially useful for synthetic modifications and may help to guide the use of pyrolysis oil as a chemical feedstock. The approach described is expected to be generally applicable to complex mixture of hydrocarbon oils such as bio-oils, oil sands bitumen, and coal pyrolysis oils.
\end{abstract}

\section{Introduction}

Due to the extremely complex nature of nonconventional oils such as bio-oils, oil sands bitumen, and coal pyrolysis oils, structural and compositional analysis of these oils poses a formidable challenge to analytical chemists. A detailed analysis requires careful, laborious combination and integration of voluminous chromatographic and spectroscopic data. Complete analysis of all components of a complex oil containing nonvolatile and/or highly polar or reactive components is generally not within the reach of current analytical methodologies. Although in recent years impressive advances have been made with the physical coupling of two or more chromatographic and/or spectroscopic techniques, such as gas chromatography-mass spectrometry (GC/MS), liquid chromatography-mass spectrometry (LC/MS), and gas chromatography-Fourier transform infrared spectroscopy (GC/FTIR), true integration of the analytical data from these methods is too complex and laborious and is rarely even attempted.

Recently, nuclear magnetic resonance (NMR) spectroscopy has emerged as a very powerful and versatile tool for characterization [1-3]. In contrast to most used characterization methods such as chromatography and mass spectroscopy, NMR allows the investigations in solids as well as in solution. Also, over the last few decades, NMR hardware, computer technology, and experimental design have developed simultaneously thus producing modern generation of NMR spectrometers capable of probing complex structures. This has resulted in substantial improvements in the processing and display of spectral data. This has allowed the simplification of complex NMR spectra.

As an alternative to the conventional analysis, NMR spectrometry method does not require sample pretreatment and thus reduces considerably manipulation time. It is also considered environmentally friendly as it enables the use of minimum amount of solvents with practically no waste generation compared, for instance, to chromatographic methods. NMR method is also capable of simultaneously detecting and quantifying a number of constituents in a single spectrum. The direct NMR spectrometry quantitative method presents advantages over some routine methods: simplicity; rapidity; selective recognition; and quantitative determination of metabolites in complex biological matrixes [4]. Quantitative 
${ }^{1} \mathrm{H}$ NMR spectrometry has been reported for the analysis of natural products, such as olive oil, fruit juice, ginkgo, and ginger powder [5-8]. The use of NMR spectroscopy as a routine analytical tool for process optimization or to follow the progress of separation/extraction efficiency of a particular compound or a group of compounds such as phenols or lignin from bio-oils would be highly desirable.

Bio-oil may be more valuable as a raw material for the manufacturing of value-added chemicals and products than as a fuel. If bio-oils are to be a future source of chemicals production, effective separation methods must be developed to generate fractions of similar polarity and to concentrate the valuable components. In this investigation, we have attempted to assess the feasibility of the preferential concentration of valuable components of two biomass based pyrolysis oil samples by progressive extraction with increasingly polar solvents. NMR data was used to estimate the concentrations of various chemical functional groups in the extracts.

Severe peak overlap in the NMR spectra of complex materials is a detriment to quantization and characterization. However, it is possible to get valuable quantitative information within $\pm 10 \%$ precision, by integrating peak clusters representing specific hydrogen or carbon types [9]. This offers a powerful tool for the characterization of complex oils. The objective of this investigation was to test the application of this novel NMR method to compare the separation and solvent extraction efficiency of two biomass based pyrolysis oil samples and their characterization. The spectra were integrated over spectral regions to quantify classes of carbon and hydrogen atoms in each oil sample.

\section{Experimental Methods}

2.1. Materials. Two biomass based oil samples used for this investigation were kept in a cold, dark refrigerator at $5^{\circ} \mathrm{C}$ in tightly closed glass bottles. Solvents and reagents used in this investigation were obtained from Aldrich and were of 99$99.8 \%$ purity (verified by capillary GC).

2.2. Total Methanol Insolubles [10]. Total methanol insolubles (solids content sometimes referred to as char) were determined using modified Dean-Stark method with methanol as solvent for $\sim 24 \mathrm{hrs}$. [11-13]. Whatman $43 \times 123 \mathrm{~mm}$ cellulose double thickness extraction thimbles were used for this investigation. Prior to use, 3 rolled Kimwipes were inserted into thimble. Thimble was placed in a weighing bottle and dried, uncapped, for 1 hour at $120^{\circ} \mathrm{C}$. After drying, the weighing bottle was capped and stored in desiccators until needed. At the time of use, weighing bottle plus thimble was weighed to the nearest $0.001 \mathrm{~g}$ and placed in its support basket after removing Kimwipes. Bio-oil sample was transferred to the thimble. Sample bottle was wiped with Kimwipes and Kimwipes were then placed in the thimble. Sample weight was determined from the weights of sample bottle before and after transfer. Heat with methanol and maintain the reflux for 24 hours or until the solvent (methanol) dripping from the thimble becomes colorless. Remove the thimble from its

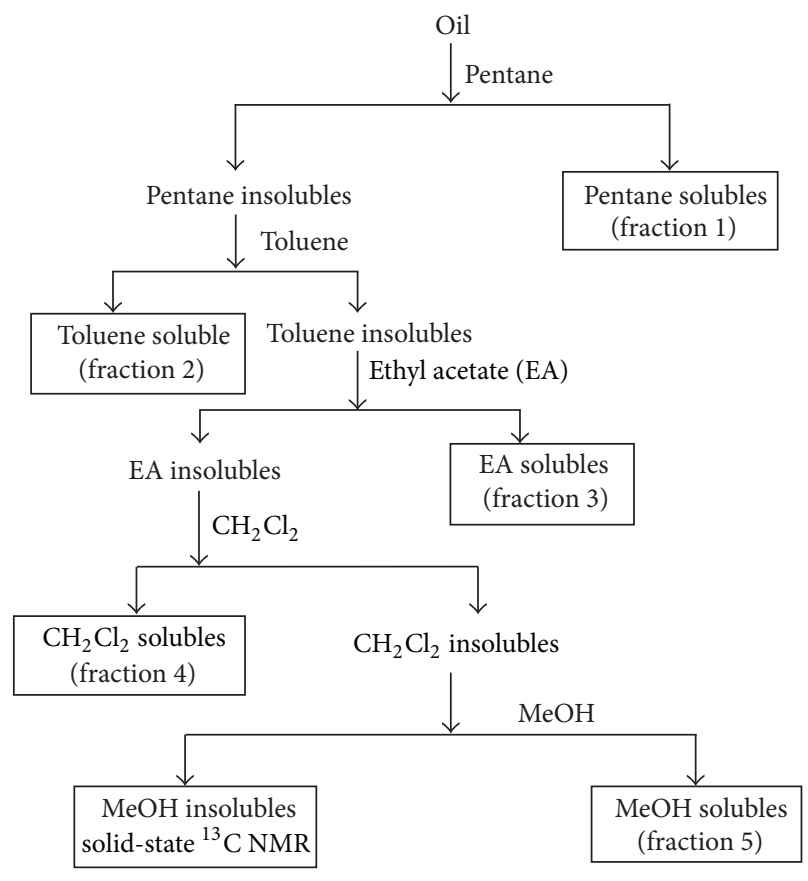

FIGURE 1: Solvent extraction scheme.

support and return it to its original weighing bottle. Dry at $120^{\circ} \mathrm{C}$ in the uncapped weighing bottle. Cool it in a desiccator and weigh it to the nearest $0.001 \mathrm{~g}$ to estimate the methanol insolubles. This represents solids (char) content of bio-oil sample.

2.3. Fractionation. Fractionation was carried out according to the scheme shown in Figure $1.20 \mathrm{~g}$ of oil was successively extracted in different solvents using soxhlet extraction [12, 13]. soxhlet extraction apparatus consisted of a $500 \mathrm{~mL}$ glass bottle (kettle) and a double thickness cellulose thimble. The sample was transferred to the thimble as described under total methanol insolubles. It was then separated into soluble oil, water, and insoluble by refluxing with the solvent in an extraction apparatus. Condensed solvent and codistilled water were continuously separated in a trap, with the water being retained in the graduated section of the trap. The solvent recycled through the extraction thimble of the extraction apparatus to dissolve the oil. The resulting oil/solvent and nonfiltered solids fractions were separated by centrifuging. The solids (solvent insoluble) were determined gravimetrically by combining the contributions for solids retained by the extraction thimble and for the nonfiltered solids. The trap and its contents (water) were cooled to room temperature and the volume of water in the trap was estimated to the nearest $0.05 \mathrm{~mL}$. These values compared well with the Karl Fisher titration value (ASTM D-1744). The solvent was removed from each extract by rotary evaporator and the residue was dissolved in deuterated chloroform for NMR investigation.

2.4. Physicochemical Properties. The water content of the oil samples was determined by Karl Fisher titration (ASTM D1744). The viscosity was measured by ASTM D445. Carbon, 
$\mathrm{H}, \mathrm{N}$, and $\mathrm{S}$ were determined using a LECO CHNS-932 analyser. Ash content of the oil was determined according to ASTM method D-482.

2.5. NMR. NMR analyses were recorded on a Varian Unity Inova spectrometer at a resonance frequency of $399.961 \mathrm{MHz}$ for ${ }^{1} \mathrm{H}$ and $100.579 \mathrm{MHz}$ for ${ }^{13} \mathrm{C}$ using a $5 \mathrm{~mm}$ pulsed field gradient indirect detection probe or a $10 \mathrm{~mm}$ broadband probe. ${ }^{1} \mathrm{H}$ and ${ }^{13} \mathrm{C}$ NMR spectra were obtained from samples dissolved in $\mathrm{CDCl}_{3}$. The solvent signals $\left(\mathrm{CDCl}_{3}{ }^{1} \mathrm{H} 7.25 \mathrm{ppm}\right.$, $\left.{ }^{13} \mathrm{C} 77.00 \mathrm{ppm}\right)$ were used as the internal reference. The peak areas of the spectra were determined by cutting and weighing the desired regions of such spectra that were expanded ten times in the $x$-axis direction. The values may not be absolute because of signal overlapping. In the case of the examined samples with identical recording conditions and quantification techniques, however, the signal intensity values are comparable between the samples.

\section{Results and Discussion}

The physicochemical characteristics of the two biomass derived pyrolysis oil samples investigated by NMR are summarized in Table 1. Both samples were progressively extracted with increasingly polar solvents using a scheme shown in Figure 1. A comparison of the extraction efficiency in various solvents suggests that the maximum amount of the oil was extracted in methanol followed by toluene. Also, there were considerably more solvent extractables from bio-oil sample 2 as compared to sample 1 . The amount of extractables, solvent insoluble, and water did not add up to $100 \%$ of the initial weight of oil. A considerable amount remained unaccounted for and was presumed to be low boiling volatiles lost during solvent removal stage. Compared with bio-oil sample 2, there were considerably more low boiling volatiles in bio-oil sample 1.

The extracts were analyzed by NMR to estimate the concentrations of various chemical functional groups that are potentially useful for synthetic modifications in using bio-oil as a chemical feedstock. The method is based on the assumption that although the number of individual molecular species in the bio-oil samples is large, most of these species are composed of a limited number of functional groups. The relative concentrations of the functional groups may provide useful information to assess the bio-oil as a chemical feedstock for the potential end products. The individual spectra and subspectra were divided into smaller sections based on the chemical shift ranges that correspond to different chemical functional groups, and this was followed by integration. The integrated peak areas in each section were then calculated as percentage of total peak area of the whole spectrum. This was assumed to be proportional to the concentration of compounds in the section [13]. The assignments are based on published work [14-21].

The comparative proton NMR spectra of various extracts from two biooil samples are shown in Figures 2(a) and 2(b), and the integral values of selected regions of the spectra on a percentage basis are presented in Table 2. A comparison
TABLE 1: Physicochemical properties of bio-oil samples investigated.

\begin{tabular}{lcc}
\hline Analysis & Sample 1 & Sample 2 \\
\hline $\mathrm{pH}$ & 3.3 & 3.6 \\
Water (wt\%) & 26.7 & 30.5 \\
Pentane soluble (wt\%) & 5.2 & 3.3 \\
Toluene soluble (wt\%) & 6.3 & 9.8 \\
$\mathrm{CH}_{2} \mathrm{Cl}_{2}$ solubles (wt\%) & 5.9 & 4.9 \\
Ethyl acetate soluble (wt\%) & 6.1 & 6.1 \\
Methanol solubles (wt\%) & 15.7 & 22.5 \\
Solvent insolubles (wt\%) & 3.4 & 0.4 \\
Low volatile organics ${ }^{*}(w t \%)$ & 30.7 & 22.5 \\
Density (kg/m ${ }^{3}$ ) & 1.22 & 1.13 \\
Viscosity, cSt & 24 & 18 \\
$\mathrm{C}$ (wt\%) & $44.3(66)$ & $34.7(72)$ \\
$\mathrm{H}$ (wt\%) & $6.8(6.7)$ & $6.9(3.4)$ \\
$\mathrm{N}$ (wt\%) & $0.15(0.1)$ & $0.1(0.2)$ \\
$\mathrm{S}$ (wt\%) & $0.31(0.5)$ & $0.26(0.3)$ \\
$\mathrm{C} / \mathrm{H}$ & $6.5(9.8)$ & $5.1(21.1)$ \\
Ash (wt\%) & 1.5 & 0.18 \\
Oil content (MeOH extractable), (wt\%) & 55.8 & 58.4 \\
MeOH insolubles, (wt\%) & 3.4 & 0.4 \\
\hline
\end{tabular}

${ }^{*}$ By difference, calculated as 100 - (total extractables recovered + water + solvent insolubles).

Values in parenthesis are for methanol insoluble solids.

of these results suggests that there are no major differences in the overall chemical makeup of the two biooils. The most upfield region of the spectra, from 0 to $4.4 \mathrm{ppm}$, representing aliphatic protons that are attached to carbon atoms, at least two bonds, removed from a $\mathrm{C}=\mathrm{C}$ double bond or heteroatom ( $\mathrm{O}$ or $\mathrm{N})$ as well as protons on carbon atoms next to an aliphatic alcohol or ether, or a methylene group that joins two aromatic rings, was most populated for both samples. The later moiety would exist in partially decomposed lignin oligomer present in the bio-oil [17]. It has been reported that aliphatic portions of molecules, even those bonded to aromatic portions or near heteroatoms, are more prevalent for the higher energy containing bio-oils [15]. The data suggests a significant amount of higher energy containing components in these bio-oils. The data also indicates limited selectivity for some components. Alcohols, ethers, and carbohydrate components appear to be more concentrated in polar solvents such as methanol, ethyl acetate, and methylene chloride compared with nonpolar solvents such as pentane and toluene. Aromatic and phenolic components were more concentrated in nonpolar solvents. Extracts from sample 1 had relatively higher concentrations of aldehyde, ketone, and acid components than sample 2 .

The bar chart in Figure 3 compares the total amount of various functional groups after taking into account the extract yield in different solvents. The highest amounts of aliphatic components (region between $0-4.4 \mathrm{ppm}$ ) were extracted in methanol followed by toluene. The extracts in other solvents had the least amount of protons in this category. 
TABLE 2: \% of $\mathrm{H}$ based on ${ }^{1} \mathrm{H}$ NMR analysis of bio-oil extracts in various solvents*.

\begin{tabular}{|c|c|c|c|c|c|c|c|c|c|c|c|}
\hline \multirow{3}{*}{ Chemical shift range (ppm) } & \multirow{3}{*}{ Proton assignments } & \multicolumn{10}{|c|}{ \% Distribution } \\
\hline & & \multicolumn{2}{|c|}{ Pentane } & \multicolumn{2}{|c|}{ Methanol } & \multicolumn{2}{|c|}{ Ethyl acetate } & \multicolumn{2}{|c|}{$\mathrm{CH}_{2} \mathrm{CH}_{2}$} & \multicolumn{2}{|c|}{ Toluene } \\
\hline & & S1 & S2 & S1 & S2 & $\mathrm{S} 1$ & S2 & $\mathrm{S} 1$ & S2 & S1 & S2 \\
\hline $0-4.4$ & Aliphatics & 78 & 81 & 69 & 72 & 65 & 64 & 67 & 72 & 77 & 72 \\
\hline $4.4-6.0$ & Alcohols, ethers, carbohydrates & 9 & 7 & 18 & 19 & 24 & 23 & 22 & 17 & 8 & 9 \\
\hline $6-8.5$ & Aromatics, olefins, phenols & 12 & 11 & 10 & 8 & 9 & 12 & 8 & 10 & 12 & 18 \\
\hline $8.5-11.0$ & Aldehydes, ketones, acids & 1 & 1 & 3 & 1 & 2 & 1 & 3 & 1 & 3 & 1 \\
\hline Yield, w/w\% of total & & 3.3 & 5.2 & 22.6 & 17.7 & 6.1 & 6.1 & 4.9 & 5.9 & 9.8 & 6.3 \\
\hline
\end{tabular}

${ }^{*}$ Grouped according to chemical shift range; S1, S2 = bio-oil samples 1 and 2.

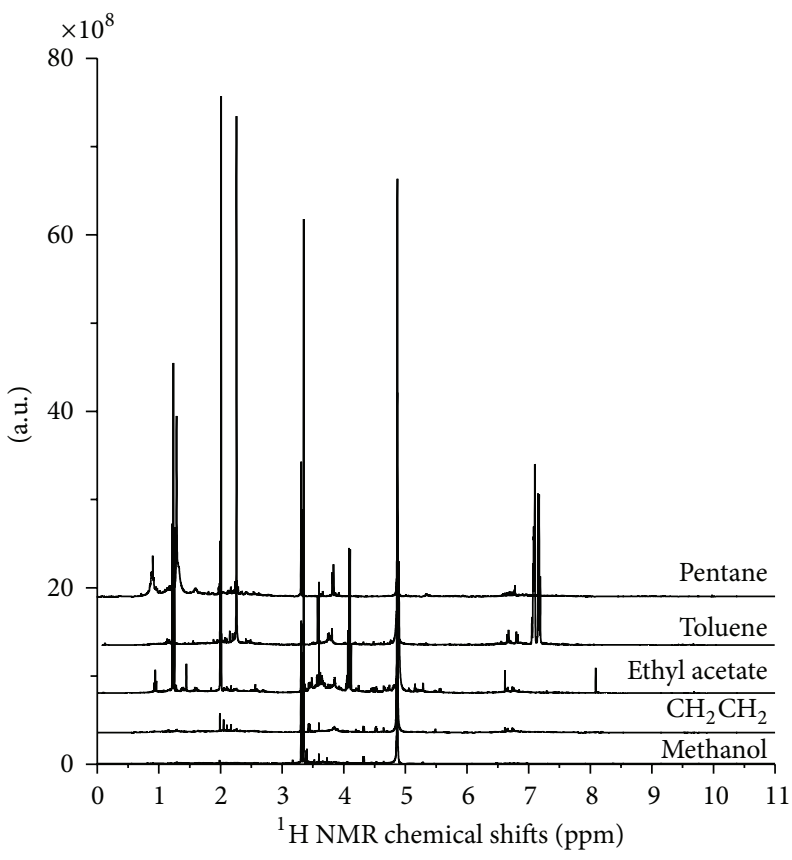

(a)

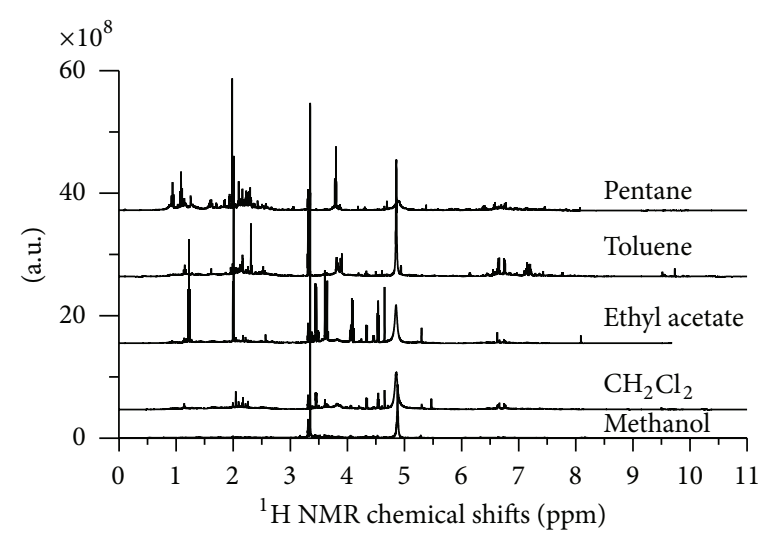

(b)

FIgURE 2: Comparative ${ }^{1} \mathrm{H}$ NMR of biooil samples in various solvents. (a) Sample 1. (b) Sample 2.

The region between 4.4 and $6.0 \mathrm{ppm}$ represents aromatic ether protons (i.e., lignin derived methoxyphenols) and many of the hydrogen atoms of carbohydrate-like molecules. These protons are also most prevalent for methanol followed by ethyl acetate and are found in smaller amounts in other solvents.

The region between 6 and $8.5 \mathrm{ppm}$ in the spectrum represents aromatics, olefins, and lignin derived phenolics. This region may be important for potential end products made from bio-oil. The distribution of these protons essentially follows the same trend as aliphatics.

The downfield spectral regions $(8.5-11 \mathrm{ppm})$ of the extracts contain resonances that most likely arise from aldehydes, ketones, and carboxylic acids. The proton NMR data suggests a slightly different distribution pattern in this region. Most of these components are present in methanol extract followed by toluene extract. All other extracts have very little amounts of these components.
The data presented in Figure 3 suggests that the selective concentration of the potentially useful components from bio oil samples solely by the solvent extraction scheme used in this investigation may not be feasible. However, a selective separation scheme could start with methanol extract as it contained the highest concentration of all components. For example, the formation of inclusion complexes with cyclodextrins could be worth exploring as one of the potentially promising inexpensive methods for the selective separation of aromatics from methanol extract [22-24].

Bio-oil sample 1 and char were also investigated using ${ }^{13} \mathrm{C}$ NMR spectroscopy for comparison purposes. The ${ }^{13} \mathrm{C}$ NMR spectra of these samples are shown in Figure 4. The data from integration values of various regions are tabulated in Table 3. Table 3 provides an overview of the entire carbon content within a given chemical shift range, providing information on the types of chemical functional groups that are present in that range, as well as their relative amounts. The percentage 
TABLE 3: Percentage distribution of carbon based on ${ }^{13} \mathrm{C}$ NMR data for char and bio-oil sample 1.

\begin{tabular}{|c|c|c|c|c|c|c|c|}
\hline \multirow{2}{*}{${ }^{13} \mathrm{C}$ Chemical shift range (ppm) } & \multirow{2}{*}{ Assignments } & \multicolumn{6}{|c|}{ \% Distribution } \\
\hline & & Pentane & Methanol & Ethyl acetate & $\mathrm{CH}_{2} \mathrm{CH}_{2}$ & Toluene & Char \\
\hline $0-60$ & Aliphatics & 41 & 36 & 42 & 37 & 38 & 26 \\
\hline $60-110$ & Alcohols, ethers, and carbohydrates & 47 & 49 & 47 & 41 & 40 & 27 \\
\hline $110-165$ & Aromatics, olefins, and phenols & 10 & 14 & 7 & 19 & 19 & 34 \\
\hline $165-220$ & Aldehydes, ketones, and acids & 2 & 1 & 4 & 3 & 3 & 13 \\
\hline $60-80$ & Intact carbohydrates & 9 & 11 & 20 & 8 & 14 & 8 \\
\hline
\end{tabular}

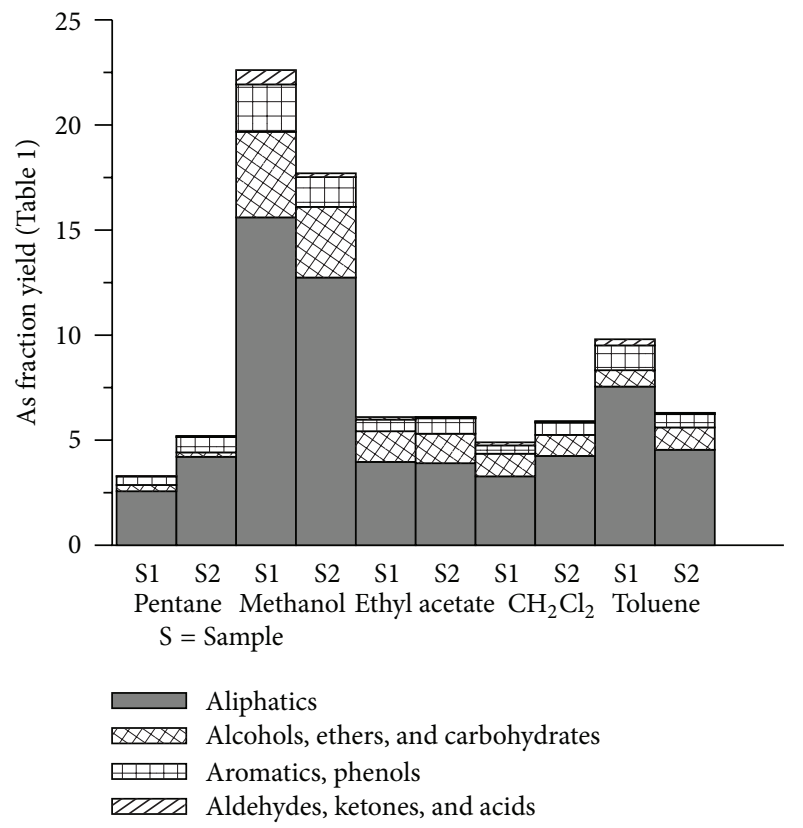

Figure 3: Total amount of functional group distribution from proton NMR data.

values in the upfield regions listed in Table 3 for the biooil extracts do not agree well with those from ${ }^{1} \mathrm{H}$ NMR as seen from a comparative plot in Figure 5. In general, the values for aliphatic region obtained from ${ }^{13} \mathrm{C}$ NMR data are a lot lower compared with the corresponding values obtained from proton NMR data. The amounts of carbon in the ether, alcohols, and carbohydrate region are a lot higher than of the corresponding hydrogen. However, the total of the two regions compares well, suggesting that the arbitrary assignments for the two data sets may not be compatible.

Contrary to upfield regions, there is much better comparison between the downfield regions of the ${ }^{1} \mathrm{H}$ and ${ }^{13} \mathrm{C}$ NMR data sets. This could be significant because the detection and relative quantification of aldehydes and ketones provide potentially useful information for applications involving the synthetic modification of bio-oils [15].

A comparison of the ${ }^{13} \mathrm{C}$ NMR data for char and solvent extracts suggests the following.

(a) Aliphatics, ethers, and alcoholic components are enriched in solvent extracts but depleted in the char.

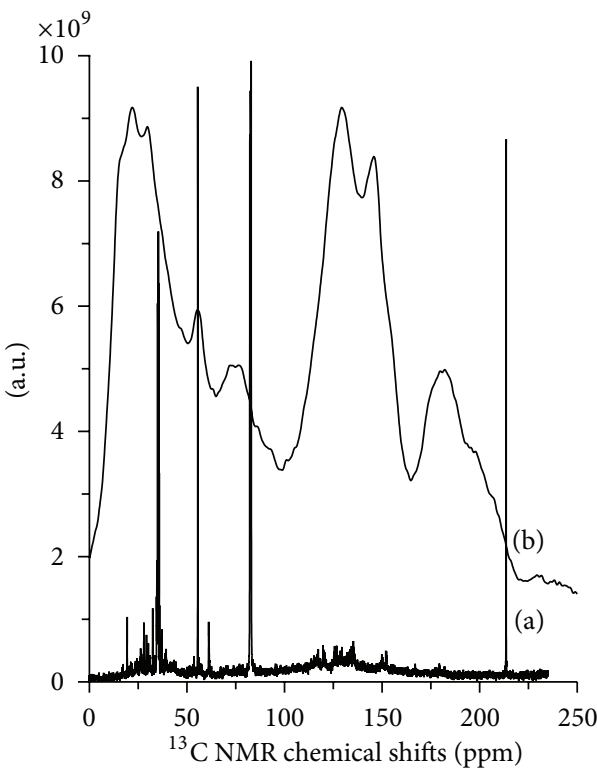

FIGURE 4: ${ }^{13} \mathrm{C}$ NMR spectra of bio-oil sample 1. (a) Solution in $\mathrm{CDCl}_{3}$, (b) solid-state char.

(b) Aromatics, aldehydes, ketones, and acidic components are enriched in the char fraction.

Thus, extracts could be source of higher energy fuels, while char can be used as a feedstock for value-added chemicals [15].

The presence of intact carbohydrates estimated from carbons found between 60 and $80 \mathrm{ppm}$ may represent an important consideration for some end products [15]. Table 3 lists the amount of intact carbohydrates estimated from ${ }^{13} \mathrm{C}$ NMR data. The highest amount of intact carbohydrates (20\%) was found in ethyl acetate extract, suggesting that selective extraction of these components by solvent extraction may be feasible.

\section{Summary and Conclusions}

The NMR data for the two bio-oil samples investigated demonstrates that it can provide important information about not only the kinds of chemicals in bio-oils but also their relative concentrations. A combination of ${ }^{1} \mathrm{H}$ and ${ }^{13} \mathrm{C}$ NMR techniques is expected to offer a powerful tool for the characterization of bio-oils. 


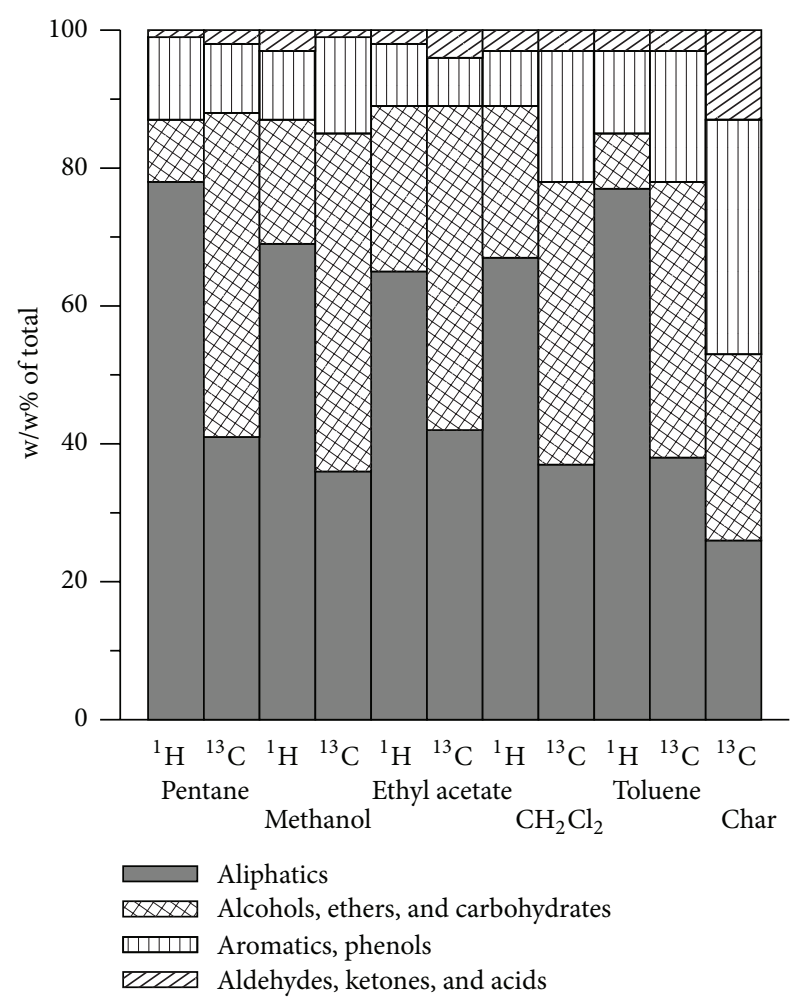

Figure 5: Comparison of ${ }^{1} \mathrm{H}$ and ${ }^{13} \mathrm{C}$ NMR data for sample 1.

A solvent extraction scheme employing extraction with increasingly polar solvents was tested for preferential concentration and separation of valuable components of two biomass based pyrolysis oil samples. Proton NMR spectroscopy was employed to characterize extracts and to measure the extraction efficiency of various solvents. The analyses of the NMR data led to the following conclusions.

(1) The maximum amount of the oil was extracted in methanol followed by toluene. Also, there were considerably more solvent extractables from bio-oil sample 2, as compared to sample 1 .

(2) Compared with bio-oil sample 2, there were more low boiling volatiles in bio-oil sample 1 .

The NMR data allowed semi-quantitative estimation of the various functional groups by integrating peak clusters representing specific hydrogen types. The method is capable of simultaneously detecting and quantifying a number of chemical functionalities in a single spectrum. The spectra were divided into four regions corresponding to specific functionalities.

Region 1, 0-4.4 ppm, represents aliphatic protons that are associated with higher energy containing components significant for the use of oil as a fuel; region 2, 4.4$6.0 \mathrm{ppm}$, represents protons belonging to alcohols, ethers, and carbohydrates; region 3, 6-8.5 ppm, represents aromatic, olefins, and phenolic protons; and region 4, 8.5-11.0 ppm, represents aldehyde, ketone, and acidic functional groups. An examination of the ${ }^{1} \mathrm{H}$ NMR data suggests the following.
(1) There are no major differences in the overall chemical makeup of the two bio-oil samples.

(2) The major components of both bio-oil samples were aliphatic protons that contribute to higher energy and make the oil suitable as a fuel.

(3) Alcohols, ethers, and carbohydrate components were more concentrated in polar solvents such as methanol, ethyl acetate, and methylene chloride compared with nonpolar solvents such as pentane and toluene.

(4) Nonpolar solvents extract more aromatics.

(5) Aldehyde, ketones, and acids were mostly present in methanol extract followed by toluene. All other extracts had very little amount of these components.

(6) Compared with sample 2, the extracts from sample 1 had relatively higher concentrations of aldehydes, ketones, and acidic components.

(7) Lignin derived methoxy protons and many of the hydrogen atoms of carbohydrate like molecules were more prevalent in methanol extract followed by ethyl acetate.

In conclusion, the ${ }^{1} \mathrm{H}$ NMR data suggests that the selective concentration of potentially useful components from bio-oil samples solely by the solvent extraction scheme used in this investigation may not be feasible. However, based on our previous work [22-24], it may be possible to develop a potentially promising selective separation method for value-added chemicals from aromatics rich fractions using cyclodextrins. Methanol extract can also be used as a feedstock for the selective separation of aromatics using cyclodextrins complexation process.

The percentage of functional groups calculated from ${ }^{1} \mathrm{H}$ and ${ }^{13} \mathrm{C}$ NMR data in the upfield regions did not compare well because of the noncompatibility of the arbitrary NMR chemical shift assignments in the two data sets. However, the comparison in the downfield regions was much better.

A comparison of the ${ }^{13} \mathrm{C}$ NMR data for char and solvent extracts from sample 1 suggests major differences in the overall chemical makeup of the two. Aliphatics, ethers, and alcoholic components were more prevalent in the extracts, but aromatics, aldehydes, and ketones had higher concentrations in char. This suggests that char may be used as a feedstock for value-added chemicals.

The ${ }^{13} \mathrm{C}$ NMR data also suggests the highest concentrations of intact carbohydrates in ethyl acetate extracts.

\section{Conflict of Interests}

The authors declare that there is no conflict of interests regarding the publication of this paper.

\section{Acknowledgments}

The authors are grateful to Dr. Stephen Lang for solid-state

${ }^{13} \mathrm{C}$ NMR spectra of char sample and Gilles Robertson for 
solution ${ }^{13} \mathrm{C}$ NMR spectra. This paper is supported by NRCC no. 53088 .

\section{References}

[1] J. W. Finley, S. J. Schmidt, and A. S. Serianni, NMR Applications in Biopolymers, Plenum Press, New York, NY, USA, 1990.

[2] J. Joseph, C. Baker, S. Mukkamala et al., "Chemical shifts and lifetimes for nuclear magnetic resonance (NMR) analysis of biofuels," Energy and Fuels, vol. 24, no. 9, pp. 5153-5162, 2010.

[3] G. D. Strahan, C. A. Mullen, and A. A. Boateng, "Characterizing biomass fast pyrolysis oils by ${ }^{13} \mathrm{C} \mathrm{NMR}$ and chemometric analysis," Energy and Fuels, vol. 25, no. 11, pp. 5452-5461, 2011.

[4] E. Hiltunen, L. Alvila, and T. T. Pakkanen, "Characterization of Brauns' lignin from fresh and vacuum-dried birch (Betula pendula) wood," Wood Science and Technology, vol. 40, no. 7, pp. 575-584, 2006.

[5] G. F. Pauli, B. U. Jaki, and D. C. Lankin, "Quantitative ${ }^{1}$ H NMR: development and potential of a method for natural products analysis," Journal of Natural Products, vol. 68, no. 1, pp. 133-149, 2005.

[6] G. Vlahov, "Application of NMR to the study of olive oils," Progress in Nuclear Magnetic Resonance Spectroscopy, vol. 35, no. 4, pp. 341-357, 1999.

[7] I. Berregi, G. Campo, R. Caracena, and J. I. Miranda, "Quantitative determination of formic acid in apple juices by ${ }^{1} \mathrm{H}$ NMR spectrometry," Talanta, vol. 72, no. 3, pp. 1049-1053, 2007.

[8] Y. H. Choi, H.-K. Choi, A. Hazekamp et al., "Quantitative analysis of bilobalide and ginkgolides from Ginkgo biloba leaves and Ginkgo products using ${ }^{1} \mathrm{H}-\mathrm{NMR}, "$ Chemical and Pharmaceutical Bulletin, vol. 51, no. 2, pp. 158-161, 2003.

[9] L. L. Landucci, "Quantitative carbon-13 NMR characterization of lignin 1. A methodology for high precision," Holzforschung, vol. 39, pp. 355-359, 1985.

[10] M. E. Boucher, A. Chaala, and C. Roy, "Bio-oils obtained by vacuum pyrolysis of softwood bark as a liquid fuel for gas turbines-part I: properties of bio-oil and its blends with methanol and a pyrolytic aqueous phase," Biomass and Bioenergy, vol. 19, no. 5, pp. 337-350, 2000.

[11] J. T. Bulmer and J. Starr, Syncrude Analytical Methods for Oil Sand and Bitumen Processing, Syncrude Canada, Edmonton, Canada, 1979.

[12] A. Majid and B. D. Sparks, "Total analysis of mineral wastes containing bitumen, solvent, water and solids," AOSTRA Journal of Research, vol. 1, pp. 21-29, 1984.

[13] A. Majid and J. Woods, "Rapid determination of Bitumen, Varsol and other Solvents using Proton NMR," ACS Division of Fuel Chemistry, vol. 28, no. 1, pp. 188-195, 1983.

[14] C. A. Mullen, G. D. Strahan, and A. A. Boateng, "Characterization of various fast-pyrolysis bio-oils by NMR spectroscopy," Energy and Fuels, vol. 23, no. 5, pp. 2707-2718, 2009.

[15] K. Lundquist, "1 H NMR spectral studies of lignins, quantitative estimates of some types of structural elements," Nordic Pulp and Paper Research Journal, vol. 6, pp. 140-146, 1991.

[16] K. Lundquist, "1 H NMR spectral studies of lignins," Nordic Pulp and Paper Research Journal, vol. 7, pp. 4-8, 1992.

[17] K. Lundquist and K. Stern, "Analysis of lignins by ${ }^{1} \mathrm{H}$ NMR spectroscopy," Nordic Pulp and Paper Research Journal, vol. 3, pp. 210-213, 1989.
[18] K. Lundquist, "Proton $\left({ }^{1} \mathrm{H}\right)$ NMR spectroscopy," in Methods in Lignin Chemistry, S. Y. Lin and C. W. Dence, Eds., pp. 242-249, Springer, New York, NY, USA, 1992.

[19] J. Sorvari, E. Sjöström, A. Klemola, and J. E. Laine, "Chemical characterization of wood constituents, especially lignin, in fractions separated from middle lamella and secondary wall of Norway spruce (Picea abies)," Wood Science and Technology, vol. 20, no. 1, pp. 35-51, 1986.

[20] J. B. Stothers, Carbon-13 NMR Spectroscopy, Academic Press, 1972.

[21] K. Lundquist, "NMR studies of lignins. 4. Investigation of Spruce lignin by ${ }^{1} \mathrm{H}$ NMR spectroscopy," Acta Chemica Scandinavica B, vol. 34, pp. 21-26, 1980.

[22] A. Majid and J. A. Ripmeester, "Inclusion complexes of cyclodextrins by agglomeration," United States patent no. 5070081, December 1991.

[23] A. Majid and J. A. Ripmeester, "Inclusion complexes of cyclodextrins by agglomeration," Canadian patent no. 1321192, August 1993.

[24] A. Majid and J. A. Ripmeester, "Spherical agglomeration-a novel technique for simultaneous pelletization and preparation of cyclodextrin inclusion compounds," Cyclodextrin News, vol. 4, pp. 49-50, 1990. 


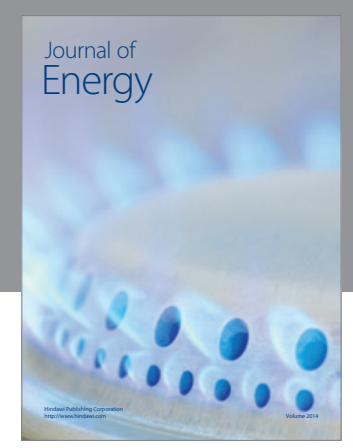

Journal of

Industrial Engineering
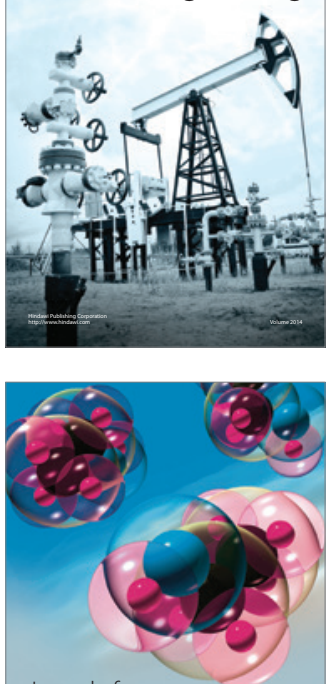

Fuels
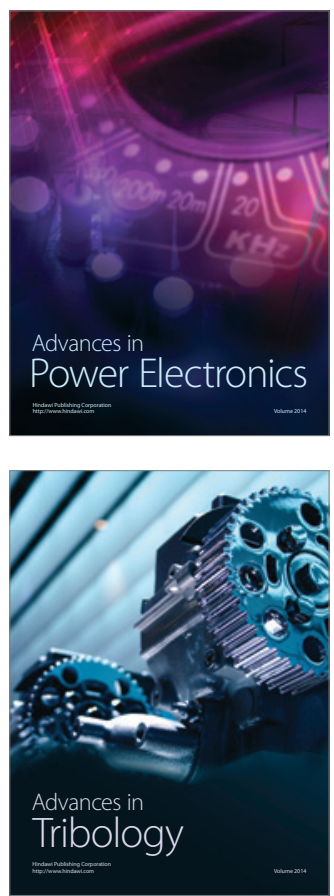

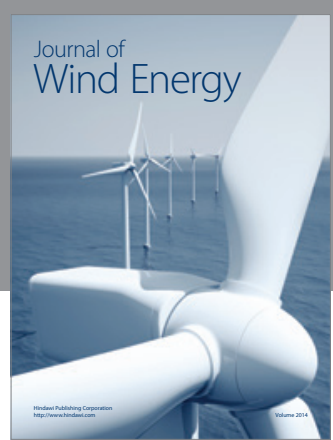

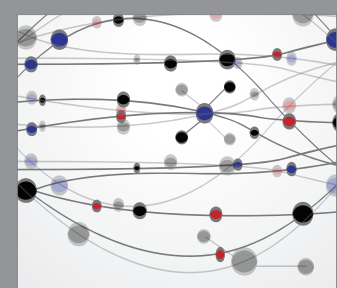

The Scientific World Journal

Submit your manuscripts at http://www.hindawi.com

Journal of

Structures
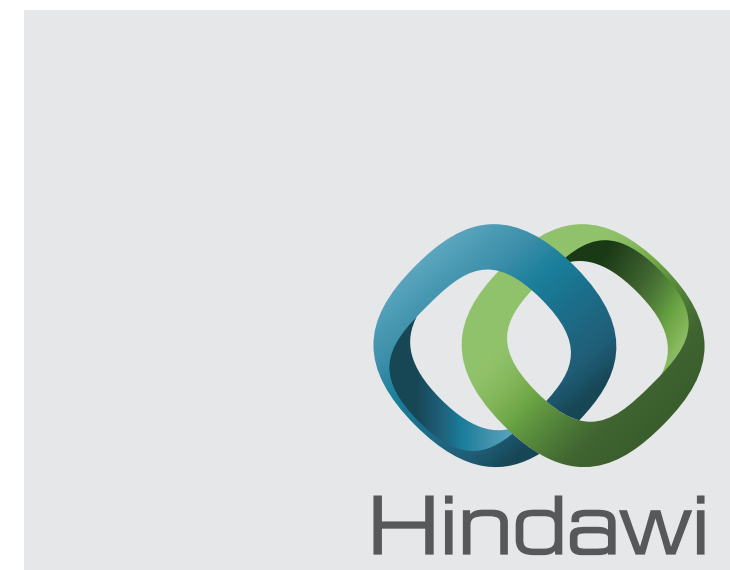

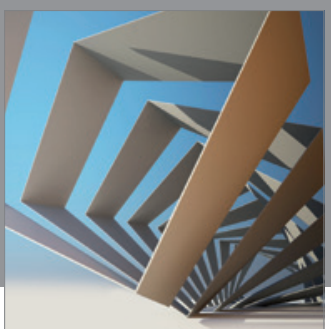

Rotating

Machinery
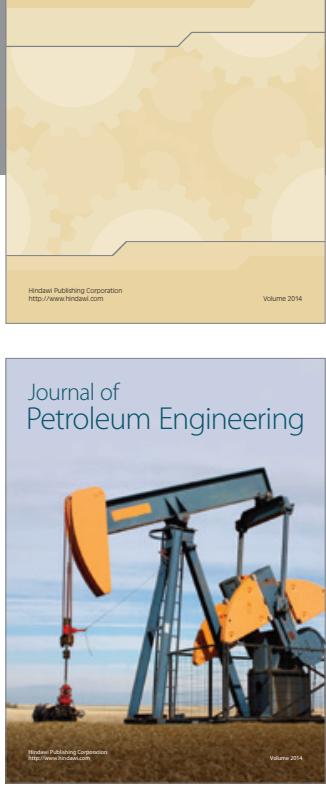

Journal of

Solar Energy
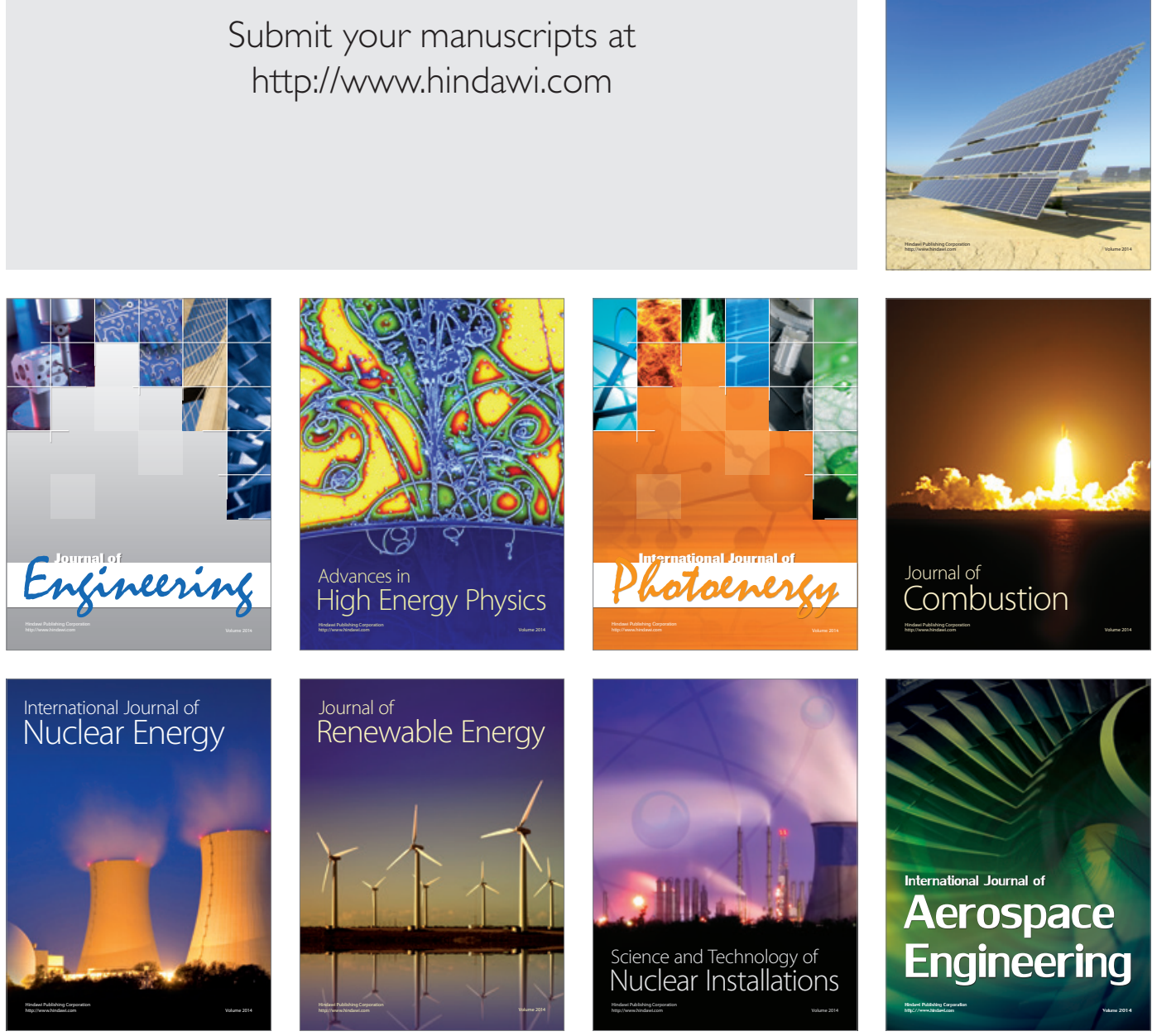